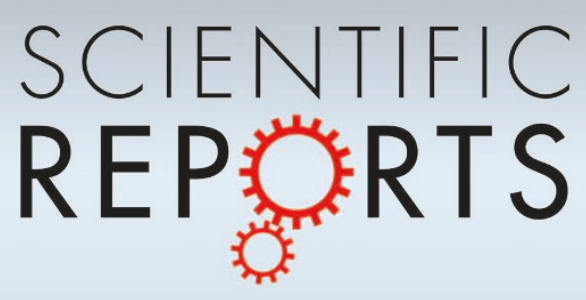

OPEN

SUBJECT AREAS:

ENERGY

MATERIALS FOR ENERGY AND

CATALYSIS

THEORY AND COMPUTATION

Received

23 June 2014

Accepted

29 August 2014

Published

19 September 2014

Correspondence and requests for materials should be addressed to H.Y. (hye@ustc.edu. $\mathrm{cn})$

\section{How to be smart and energy efficient: $A$ general discussion on thermochromic windows}

\author{
Linshuang Long \& Hong Ye
}

Department of Thermal Science and Energy Engineering, University of Science and Technology of China, Hefei, Anhui 230027, PR China.

A window is a unique element in a building because of its simultaneous properties of being "opaque" to inclement weather yet transparent to the observer. However, these unique features make the window an element that can reduce the energy efficiency of buildings. A thermochromic window is a type of smart window whose solar radiation properties vary with temperature. It is thought that the solar radiation gain of a room can be intelligently regulated through the use of thermochromic windows, resulting in lower energy consumption than with standard windows. Materials scientists have made many efforts to improve the performance of thermochromic materials. Despite these efforts, fundamental problems continue to confront us. How should a "smart" window behave? Is a "smart" window really the best candidate for energy-efficient applications? What is the relationship between smartness and energy performance? To answer these questions, a general discussion of smartness and energy performance is provided.

W indows are the most extraordinary elements of building exteriors because they can influence the occupants from not only a physiological perspective but also a psychological perspective. Similar to other elements such as walls and roofs, windows provide the occupants with a shield against inclement weather. Additionally, windows help connect the occupants and the outside world. These distinct roles necessitate that windows are simultaneously "opaque" to environmental factors that can cause discomfort and transparent to observers; they also make windows an element that can reduce the energy efficiency of buildings ${ }^{1}$. A variety of advanced windows have been developed to reduce the energy consumption used to maintain thermal comfort in buildings ${ }^{2-4}$. To set a common standard for the analysis of these windows, we have previously reported the concept of the perfect windows ${ }^{5}$ whose diagrammatic sketch is shown in Figure 1. In theory, perfect windows have the best energy performance among all windows, and their spectral properties are shown in Table 1 . The energy performance of a particular advanced window can be evaluated from a common standpoint via comparison with the perfect windows.

Based on the properties of perfect windows, two types of radiation flux must be regulated by windows: the longwave thermal radiation emitted by objects at normal temperatures, and the solar radiation emitted by the sun, at a surface temperature of $\sim 6000 \mathrm{~K}$. Low emissivity (low-e) windows, which can attenuate the propagation of longwave thermal radiation, and chromogenic windows ${ }^{6,7}$, whose solar radiation properties can change when triggered by an external stimulus, are two typical advanced windows designed to regulate these two types of radiation. A low-e window usually contains a coating with low emissivity on the indoor side of the glazing substrate ${ }^{8}$. With this coating, the long-wave thermal radiation from the outdoor environment cannot enter the room in the summer, and the thermal radiation from indoor surfaces cannot escape the room in the winter, theoretically resulting in lower energy consumption during both seasons. The thermochromic window ${ }^{9-11}$, whose transition depends on the temperature, is a widely investigated type of chromogenic window. It has two states: a transparent state with a higher solar transmittance and an opaque state with a lower solar transmittance, which are used when the window's temperature is below and above, respectively, a given transition temperature $\left(T_{\tau}\right)$. The radiation property transition feature is similar to the above-mentioned transition between the perfect window for winter and for summer, implying that the thermochromic window has the potential to have excellent energy performance. Vanadium dioxide $\left(\mathrm{VO}_{2}\right)$ is one of the most promising thermochromic materials ${ }^{6}$. Materials scientists have made many efforts to improve the properties of $\mathrm{VO}_{2}$, such as reducing the transition temperature ${ }^{12,13}$ and enhancing the visible transmittance and solar modulation ability ${ }^{14}$. Warwick et al. have pointed out that the 


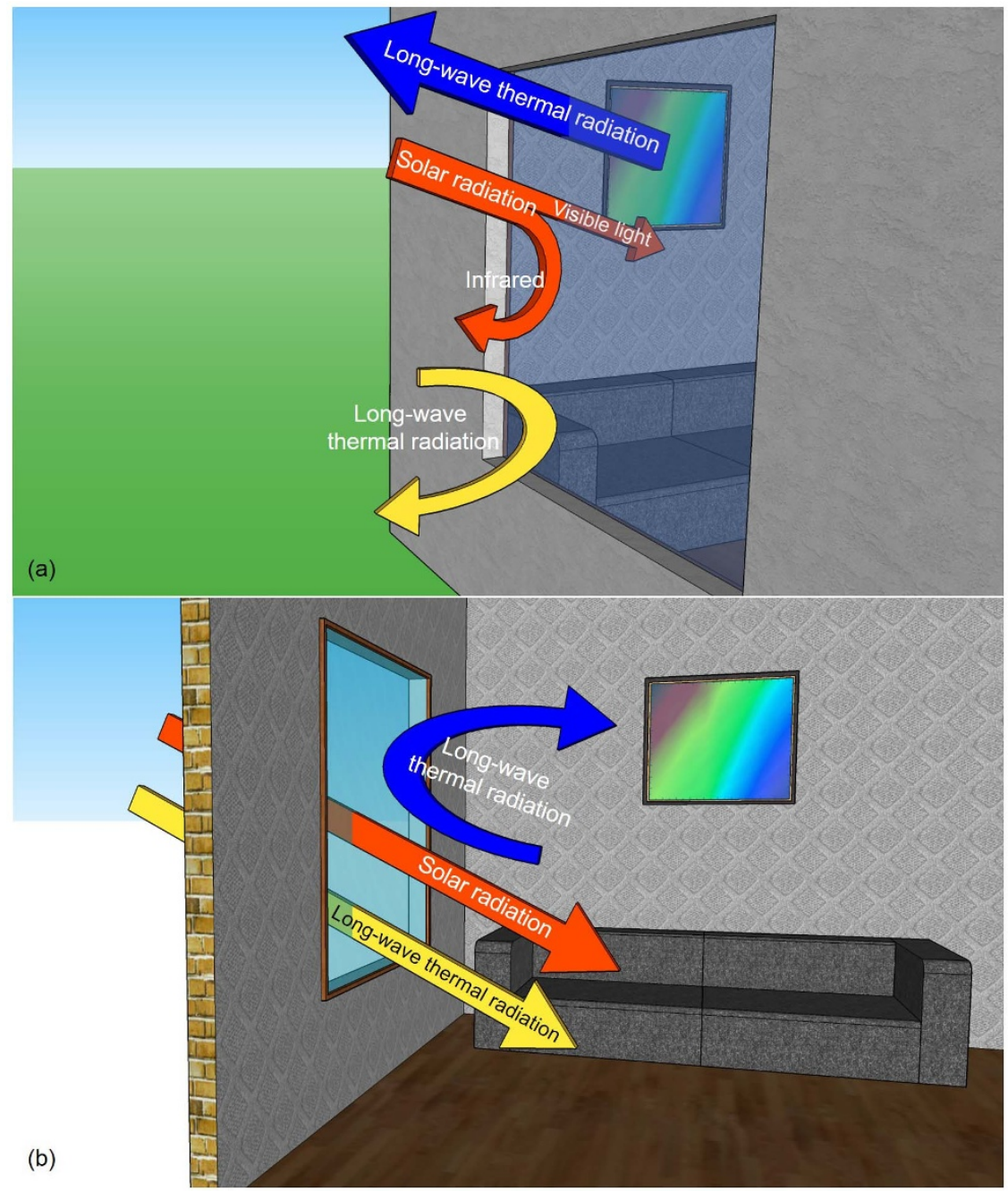

Figure 1 Diagrammatic sketch of perfect windows. The perfect windows for (a) summer and (b) winter are shown. The orange arrows represent solar radiation, the yellow arrows represent long-wave thermal radiation emitted by the outdoor environment, and the blue arrows represent the long-wave thermal radiation emitted by indoor surfaces. The perfect window for summer permits the visible light in the solar spectrum to be transmitted into the room to provide indoor illumination and enable observation, but it also reflects solar radiation in other spectra to reduce the heating of the indoor environment. Simultaneously, the long-wave thermal radiation from indoor surfaces is transmitted through the perfect window for summer, but the thermal radiation from the outdoor environment is reflected back by the window. This one-way transmission of long-wave thermal radiation allows thermal radiation to be transferred only from the indoors to the outdoors, which is advantageous for reducing the cooling load. During the heating season, the perfect window for winter transmits both the solar radiation and the long-wave thermal radiation from the outdoor environment, but it reflects the long-wave thermal radiation from the indoor surfaces. This allows the maximum possible heat compensation from the outdoors and the minimum possible heat loss from indoors. This figure was created by L.L. and revised by H.Y.

thermochromic window with an energy-efficient benefit requires an ideal transition temperature between 20 and $25^{\circ} \mathrm{C}$ as well as a high visible transmittance and solar modulation ability ${ }^{15}$. When within this idea transition temperature range, a thin transition hysteresis width and a sharp gradient of the thermochromic materials can further improve the energy-efficient performance ${ }^{16,17}$.

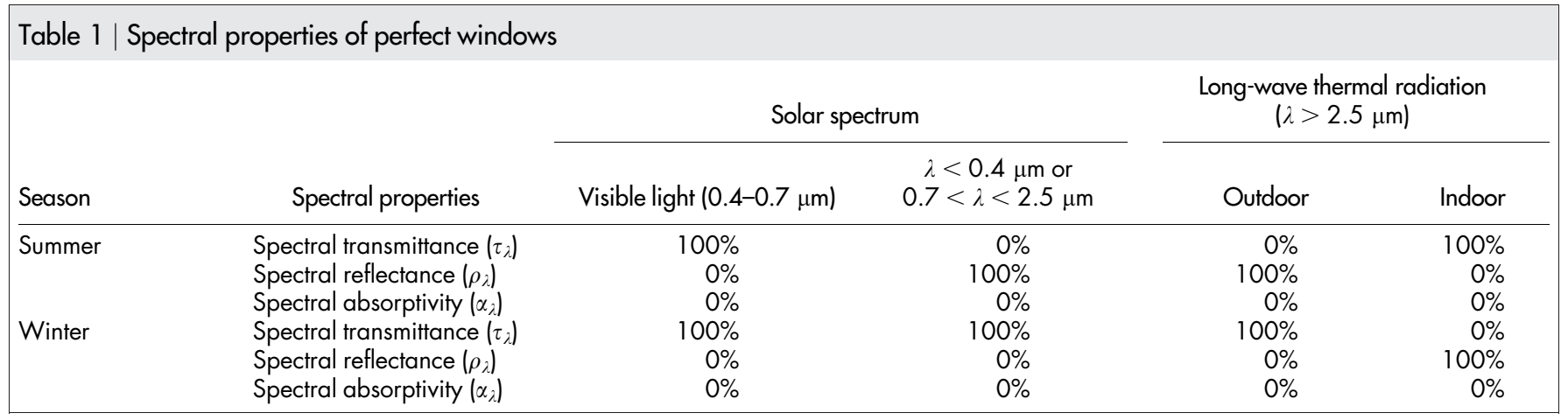


Thermochromic windows are considered "smart" devices. In some references, they are also called as "highly efficient", "switchable"13 or "intelligent" 15 windows. Here, the word "smart" is used to describe the natural ability of the windows to intelligently regulate the solar transmittance when triggered by temperature: as the temperature increases, the solar transmittance decreases to block the undesirable solar radiation. According to the law of energy conservation, radiation can be blocked through reflection and/or absorption by the window when the radiation is prevented from passing through the window. In perfect windows, the undesirable radiation is blocked by reflection. As Table 1 shows, when the spectral transmittance $\left(\tau_{\lambda}\right)$ of the undesirable radiation is zero, the corresponding spectral absorptivity $\left(\alpha_{\lambda}\right)$ is also zero, which means that the undesirable radiation is completely reflected. In most existing thermochromic windows, the undesirable radiation is blocked mainly through absorption by thermochromic materials. It is generally believed that during the summer, as the temperature increases, "smart" thermochromic windows should result in lower energy consumption because of their lower solar transmittance. However, we have discovered that the absorbed radiation can be converted into heat in the window and then transferred to the indoor environment through thermal radiation and convection, which is disadvantageous for energy efficiency in the summer. Consequently, the absorption effect may lead to increased energy consumption as the temperature increases ${ }^{5}$. This discovery leads to the requirement of a more comprehensive understanding of the "smart" thermochromic windows. It implies that not all thermochromic materials are as smart or beneficial as they were thought to be, due to the absorption effect. We have taken a step forward with another discovery that the so-called "smartness" could be estimated via the modulation of the radiation properties between different states ${ }^{18}$. However, additional important and fundamental questions remain. How should a "smart" window behave? Is a "smart" window the best candidate for energy-efficient applications? What is the relationship between smartness and energy performance? To answer these questions, we will take another step further by redefining "smartness" and discussing the relationship between smartness and energy performance.

\section{Results}

Redefinition of smartness. The definition of "smartness" has been somewhat ambiguous. For a thermochromic window, the word "smart" has usually been used to describe the window's capacity to regulate its properties, especially its solar transmittance, in response to changing temperature ${ }^{1}$. The goal of regulating the solar transmittance of a thermochromic window is actually to regulate the energy loads for both space cooling and heating and, ultimately, to achieve energy efficiency. Consequently, we would like to define "smartness" directly on the basis of the corresponding energy performance. Our new definitions of the different behavior types for thermochromic windows are listed in Table 2: The word "smart" is now used to describe the energy performance over an entire year. "Inefficient" thermochromic windows should not be used in building applications. "Efficient" windows behave like common energy-efficient windows without a smart regulation capacity, unlike smart windows, which can reduce the energy load intelligently. It should be noted that the word "advantageous" or "disadvantageous" in Table 2 implies a better or worse energy performance than a given standard. Here, the standard window is chosen to be an ordinary window of plain glass whose solar transmittance, solar absorptivity and long-wave thermal emissivity are $77.1,15.9$ and $83.7 \%$, respectively. This type of glass is commonly used in residential buildings. If the energy consumption of a room with a particular thermochromic window is less during a period of time than that with the standard window, i.e., the use of this thermochromic window is advantageous for energy efficiency, then the thermochromic window is labeled as advantageous; otherwise, it is disadvantageous. Using the new definitions, the performance of a particular thermochromic window can be labeled as a particular type from a simple perspective rather than from the complicated relationship between temperature and solar radiation properties.

Assumptions for the discussion on potential thermochromic windows. Our goal is to perform an analysis of all potential thermochromic windows to discover the general relationship between smartness and energy performance. Several parameters are needed to evaluate each thermochromic window, such as the transition temperature, the solar radiation properties in both states and the long-wave thermal radiation properties. Therefore, the number of potential thermochromic windows is theoretically infinite due to the infinite possible combinations of these parameters. To make the analysis feasible, the transition temperature is set as 10, 20, 30,40 or $50^{\circ} \mathrm{C}$. The radiation properties of each of the potential thermochromic windows at each transition temperature should then obey the following assumptions:

1. The radiation properties vary from zero to unity at an interval of 0.1 .

2. Although the long-wave thermal emissivity of thermochromic windows can be regulated with a multilayered structure ${ }^{19,20}$, the basic feature of thermochromic materials is their ability to modulate solar radiation. In this study, the long-wave thermal emissivity is set at a value of $83.7 \%$ under the assumption that the thermochromic material is plated with an ordinary glazing substrate, and the thermochromic window's emissivity is equal to that of a standard window.

3. In most current thermochromic windows, undesirable solar radiation is regulated through absorption by the thermochromic material ${ }^{21-23}$. Although it has been revealed that the high solar absorptivity in the opaque state was disadvantageous for energy efficiency ${ }^{5}$, for these thermochromic materials, the variation in the absorptivity with temperature is actually the fundamental and dominant cause of the regulation of the transmittance. Consequently, the solar absorptivity in the opaque state is greater than that in the transparent state, and the solar transmittance in the opaque state is less than that in the transparent state.

4. According to the law of conservation of energy, the sum of the solar transmittance and absorptivity is not greater than unity in either state.

Consequently, at each transition temperature, there are 1716 potential types of thermochromic windows, each with a particular combination of solar transmittance and absorptivity in the transparent state and the opaque state, respectively.

The transition temperature with the greatest proportion of smart thermochromic windows. The energy consumption performance of a typical residential room containing one of the potential thermochromic windows was simulated using an energy modeling program called BuildingEnergy (see Supplementary Figure S1 online). This room has internal dimensions of $4 \mathrm{~m} \times 3.3 \mathrm{~m} \times 2.8 \mathrm{~m}$ (length $\times$ width $\times$ height). It contains a single exterior wall facing south, in the center of which there is a $1.5 \mathrm{~m} \times 1.5 \mathrm{~m}$ single-glazed window (see Supplementary Figure S2 online). The thermochromic coating is on the outdoor surface of the glazing. The room is assumed to be in Shanghai, which is located at latitude $31 \mathrm{~N}$ and longitude $121 \mathrm{E}$ and has a cooling season from June 24 th to September 15 th and a heating season from December 6th to March 22nd of the following year. The indoor temperature of the room is maintained with heating, ventilation and air conditioning (HVAC) facilities at 18 and $26^{\circ} \mathrm{C}$ in the heating and cooling seasons, respectively.

At each transition temperature, the energy consumption of each of the potential thermochromic windows during cooling and heating 


\begin{tabular}{|c|c|c|c|}
\hline Behavior type & Cooling season & Heating season & Annual \\
\hline $\begin{array}{l}\text { Smart } \\
\text { Efficient (but not smart) } \\
\text { Inefficient }\end{array}$ & $\begin{array}{l}\text { Advantageous } \\
\text { Advantageous } \\
\text { Disadvantageous } \\
\text { Advantageous } \\
\text { Disadvantageous } \\
\text { Disadvantageous }\end{array}$ & $\begin{array}{l}\text { Advantageous } \\
\text { Disadvantageous } \\
\text { Advantageous } \\
\text { Disadvantageous } \\
\text { Advantageous } \\
\text { Disadvantageous }\end{array}$ & $\begin{array}{l}\text { Advantageous } \\
\text { Advantageous } \\
\text { Advantageous } \\
\text { Disadvantageous } \\
\text { Disadvantageous } \\
\text { Disadvantageous }\end{array}$ \\
\hline
\end{tabular}

was calculated first. The energy consumption behavior type of each window was then labeled according to the information in Table 2. The type statistics associated with each transition temperature are shown in Figure 2. The number of smart thermochromic windows first increases and then decreases as the transition temperature decreases. At a transition temperature of 50 or $40^{\circ} \mathrm{C}$, there are no smart windows, and the inefficient windows represent approximately $88 \%$ of the 1716 potential thermochromic windows. The percentage of smart windows at a transition temperature of $10^{\circ} \mathrm{C}$ is only $0.3 \%$. According to the definition of smart windows, the energy consumption of a smart window should be less than that of an ordinary window in both the cooling and heating seasons. Because the appropriate radiation properties for energy efficiency during cooling and heating are distinct, a state transition is necessary. Transition temperatures of 10,40 or $50^{\circ} \mathrm{C}$, however, are either too low or too high for a state transition to occur, maintaining the thermochromic window predominantly in a single state; consequently, it is non-smart. The negligible number of smart windows indicates the inappropriate nature of these transition temperatures.

The percentage of smart thermochromic windows increases to $\sim 5 \%$ at a transition temperature of $30^{\circ} \mathrm{C}$ and reaches a peak of $\sim 11 \%$ at $20^{\circ} \mathrm{C}$. The set points for the indoor temperature are 18 and $26^{\circ} \mathrm{C}$ for heating and cooling, respectively, and the transition temperature of $20^{\circ} \mathrm{C}$ is within this temperature range, making it convenient for state transition between different seasons. The number of efficient windows is also the largest at a transition temperature of $20^{\circ} \mathrm{C}$. As Figure 2 shows, the optimal transition temperature, at which the largest number of both smart and efficient windows exist, is $20^{\circ} \mathrm{C}$. It should also be noted that the discussed transition tem- peratures have a relatively large interval of $10^{\circ} \mathrm{C}$, which means that another transition temperature between $10 \sim 20$ or $20 \sim 30^{\circ} \mathrm{C}$ might be even better than $20^{\circ} \mathrm{C}$. Our previous study ${ }^{5}$ investigated the optimal transition temperature for an ideal thermochromic window, and we found that the optimal value was $21^{\circ} \mathrm{C}$, which is very close to $20^{\circ} \mathrm{C}$. Consequently, a transition temperature of $20^{\circ} \mathrm{C}$ may be considered appropriate for this study. The following discussion will focus on the energy performance associated with a transition temperature of $20^{\circ} \mathrm{C}$.

Energy Consumption Index frequency distribution. The Energy Consumption Index (ECI) was calculated to obtain the frequency distribution shown in Figure 3 for a transition temperature of $20^{\circ} \mathrm{C}$. The ECI is a dimensionless parameter used to evaluate energy performance ${ }^{5}$. The ECI of a particular window is defined as the ratio of the energy consumption of the room containing the window to the corresponding value of the same room with a perfect window. The ECI of a perfect window is unity, and the ECI of the standard window in this study is calculated to be 1.115 and 1.630 for the cooling and heating seasons, respectively. A higher ECI results in greater energy consumption, and an ECI closer to unity produces energy performance closer to that of the perfect window.

As Figure 3 (a) shows, at a transition temperature of $20^{\circ} \mathrm{C}$, many thermochromic windows have a lower ECI than that of the standard window during the cooling season. There are also many windows whose ECI is less than that of the perfect window during the summer. This phenomenon seems puzzling because the perfect window should, in theory, have the lowest ECI. According to Table 1, in summer, the perfect window can meet the demand of providing

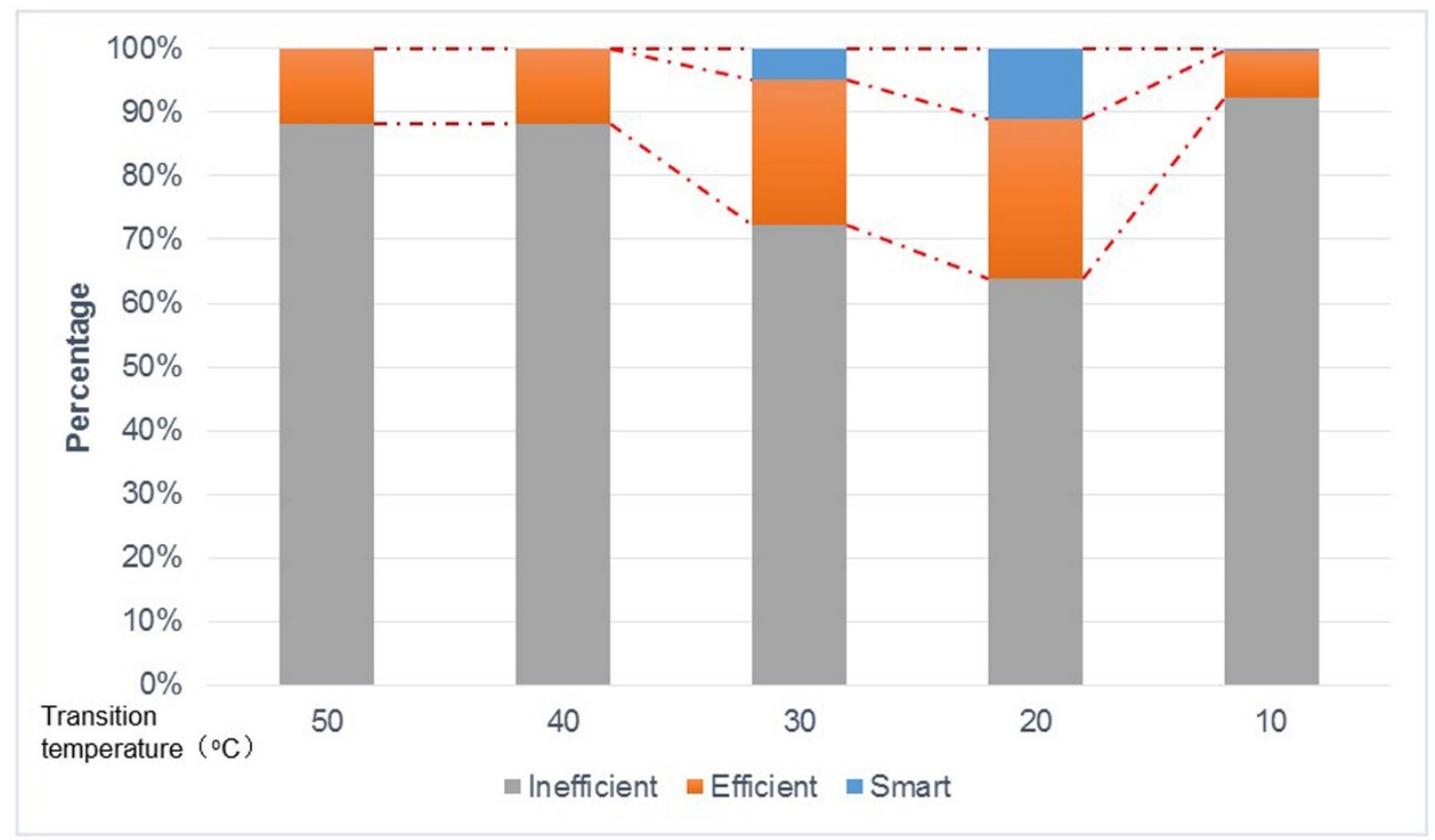

Figure $2 \mid$ Type statistics associated with the transition temperature. The percentages of each type are shown for different transition temperature values. 
illumination with a visible transmittance of $100 \%$. Because the visible part of the spectrum carries approximately $42.8 \%$ of the total solar energy $^{24}$, the solar transmittance of the perfect window for summer can be regarded as $42.8 \%$. However, thermochromic windows are discussed from the perspective of energy consumption for HVAC in this study, and the visible transmittance is integrated into the solar transmittance. As a result, if a thermochromic window has a solar transmittance that is substantially less than $42.8 \%$ (at the expense of illumination), it is possible for its ECI to be less than that of the perfect window. The thermochromic windows whose ECIs are much less than unity are generally poor choices for natural light illumination.

The distribution of ECI frequency counts in the heating season, as shown in Figure 3 (b), is quite different from that in the cooling season. Most of the thermochromic windows have higher ECIs than the standard window, and there is no ECI lower than unity. The solar transmittance of the standard window has a relatively high value of $77.1 \%$, which means that many thermochromic windows have a lower solar transmittance. Consequently, there are only a few energy-efficient windows in the heating season. With a perfect window for winter, long-wave thermal radiation can only enter but cannot leave the room; with thermochromic windows, long-wave thermal radiation can be absorbed by the window and then emitted to the outdoor environment. Because of this difference in long-wave thermal radiation characteristics, the ECIs of the thermochromic windows are always greater than that of the perfect window during the heating season.

The total energy consumption over an entire year includes both cooling and heating requirements. Considering the difference in the coefficient of performance (COP), it is inappropriate to directly sum the energy consumption for cooling and heating. In engineering design, cooling and heating consumption are generally transformed into electric power by dividing by the COP, and they can then be summed. In Shanghai, the recommended COP values for cooling and heating are 2.3 and 1.9, respectively ${ }^{25}$. The ECI of a thermochromic window over an entire year is obtained by calculating the ratio of the total energy consumption of the thermochromic window to that of the perfect window. Figure 3 (c) shows that the distribution of the annual ECI frequency is approximately normal. The ECI of the standard window is 1.384 , which is greater than approximately one-third of the potential thermochromic windows, meaning that approximately one-third of the windows are efficient or smart, consistent with the results shown in Figure 2. No thermochromic windows have a lower ECI than the perfect window. However, there are a few ECIs that are very close to unity, which indicates the possible existence of thermochromic windows with excellent energy performance. These ideal windows will be discovered step by step.

Figure 3 shows that there are many more thermochromic windows that are efficient in the cooling season $(\sim 98 \%$ of all thermochromic windows) than in the heating season $(\sim 12 \%)$. This poor performance during winter leads to only $\sim 36 \%$ of all thermochromic windows being efficient over the entire year, meaning that performance in the heating season is the critical factor for annual performance. According to the definition, smart windows should be efficient in both the cooling and heating seasons, which indicates that the number of smart windows should not exceed $12 \%$ of the total number of windows. As Figure 2 shows, the percentage is $\sim 11 \%$.

Effect of solar modulation ability on energy consumption. The overall energy consumption performance is shown in Figure 3 from a qualitative perspective. A more important issue now is the relationship between the radiation properties of the windows and their smartness. The solar modulation ability $\left(\Delta \tau_{\text {solar }}\right)$ is a key parameter for thermochromic material estimation, and it is defined as the difference in solar transmittance between the transparent state and the opaque state. Figure 4 shows the effect of the solar modulation ability on the thermochromic windows' performance at a transition temperature of $20^{\circ} \mathrm{C}$.

Figure 4 (a) shows the percentages of each behavior type at different solar modulation abilities. As $\Delta \tau_{\text {solar }}$ increases, the percentage of inefficient windows decreases, and the percentages of efficient and smart windows increase. At an appropriate transition temperature, as $\Delta \tau_{\text {solar }}$ increases, the solar transmittance will decrease during the cooling season and increase during the heating season, leading to an increased possibility for a window to be smart. This tendency confirms the advantage from a smartness perspective of enhancing a window's solar modulation ability. Such enhancement is the focus of research of many materials scientists. Smart windows appear achievable when $\Delta \tau_{\text {solar }}$ is greater than or equal to $10 \%$, indicating that $\Delta \tau_{\text {solar }}$ needs to be enhanced to at least approximately $10 \%$ to have the possibility of being a smart window. All of the windows are smart when $\Delta \tau_{\text {solar }}$ is 90 or $100 \%$; however, such high solar modulation ability values are obtained by having a very high solar transmittance in the transparent state and very low solar transmittance in the opaque state. In the extreme case, a $\Delta \tau_{\text {solar }}$ of $100 \%$ means a solar transmittance of $100 \%$ in the transparent state and one of zero in the opaque state. Note that the ordinate in Figure 4 (a) is a percentage rather than a number. The number of thermochromic windows decreases as $\Delta \tau_{\text {solar }}$ increases.

Of the three behavior types, we are most interested in the smart and efficient types, and we are especially interested in the energy consumption of these types. Figure 4 (b) shows the ECI ranges at different solar modulation abilities for the smart and efficient window types. In the figure, the height represents the ECI level on the vertical axis, and the length represents the range: the longer the bar, the larger the ECI range. The lowest ECI appears when $\Delta \tau_{\text {solar }}$ is $100 \%$. The bars for the smart and efficient types overlap one another except at $\Delta \tau_{\text {solar }}$ levels of 0,90 and $100 \%$. For each $\Delta \tau_{\text {solar }}$ value where overlap of the ECI bars occurs, the highest and lowest ECIs are presented by the efficient and smart windows, respectively, indicating that the smart windows provide better performance than the efficient ones under optimized cases. The overlap indicates that the ECIs of the smart windows are not necessarily lower than those of the efficient ones, which raises the questions of how to identify the behavior type of a particular thermochromic window and how to determine its specific ECI.

Evaluation of the behavior type and performance of a particular thermochromic window. An overview of the smartness and energy performance of all of the thermochromic windows at a transition temperature of $20^{\circ} \mathrm{C}$ was provided above. Additionally, we want to connect a particular thermochromic window with its behavior type and energy performance. It is quite a challenging task to determine a concise relationship because four parameters (the solar transmittance and absorptivity in the transparent and opaque states) are needed to characterize a particular thermochromic window in this study. It is observed from Figure 4 that the ECI is greatly affected by $\Delta \tau_{\text {solar. }}$. In fact, $\Delta \tau_{\text {solar }}$ contains two of the four parameters, suggesting that the remaining two parameters can similarly be integrated into one parameter. Here, we define the solar absorption variation $\left(\Delta \alpha_{\text {solar }}\right)$ as the difference in the solar absorptivity between a thermochromic window's two states. As shown in Figure 5 (a), with $\Delta \tau_{\text {solar }}$ as the abscissa and $\Delta \alpha_{\text {solar }}$ as the ordinate, a strong regularity is observed in the color contour between the annual ECI and the thermochromic windows' radiation properties. Each thermochromic window can be located on the contour according to its radiation properties, and its ECI can then be estimated. Note that a specific combination of $\Delta \tau_{\text {solar }}$ and $\Delta \alpha_{\text {solar }}$ may represent more than one thermochromic window, especially when $\Delta \tau_{\text {solar }}$ and $\Delta \alpha_{\text {solar }}$ are small. The overlapping ECI values for identical coordinates are averaged to obtain a statistical value. The coefficient of variation, defined as the ratio of the standard deviation to the mean, can be used to measure the dispersion of ECIs 


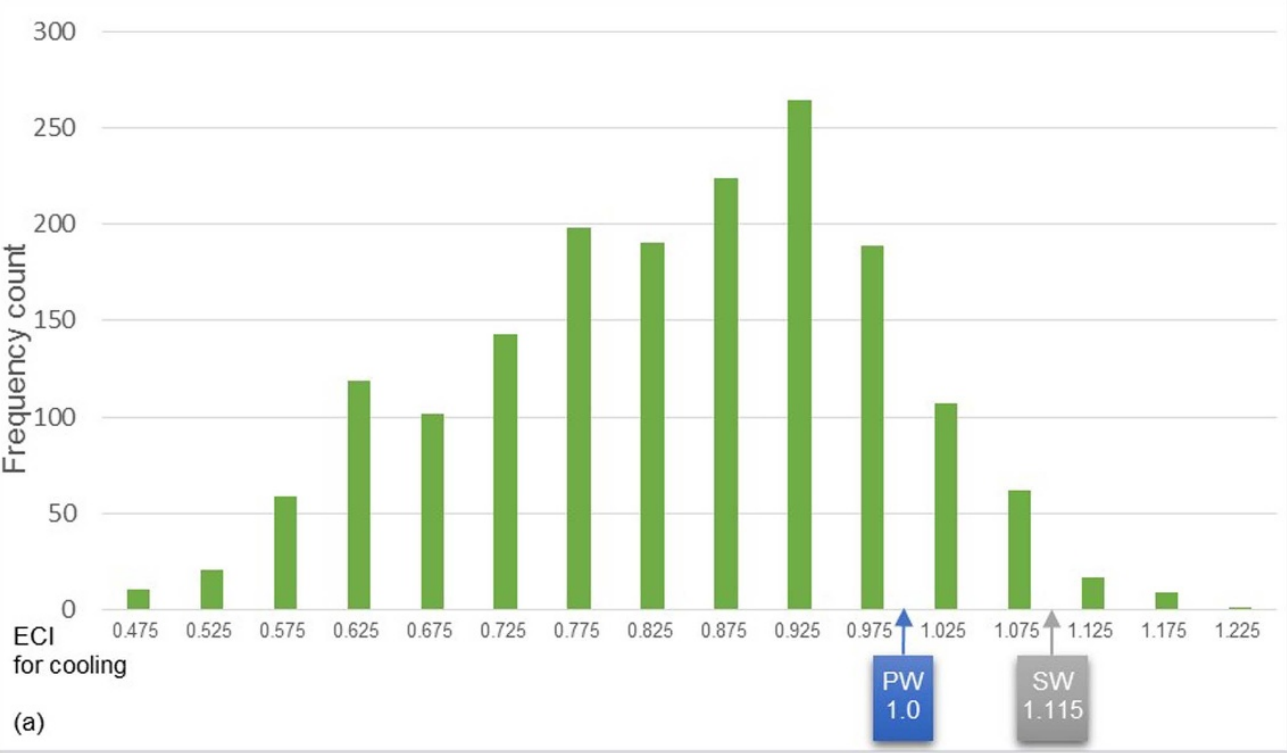

(a)
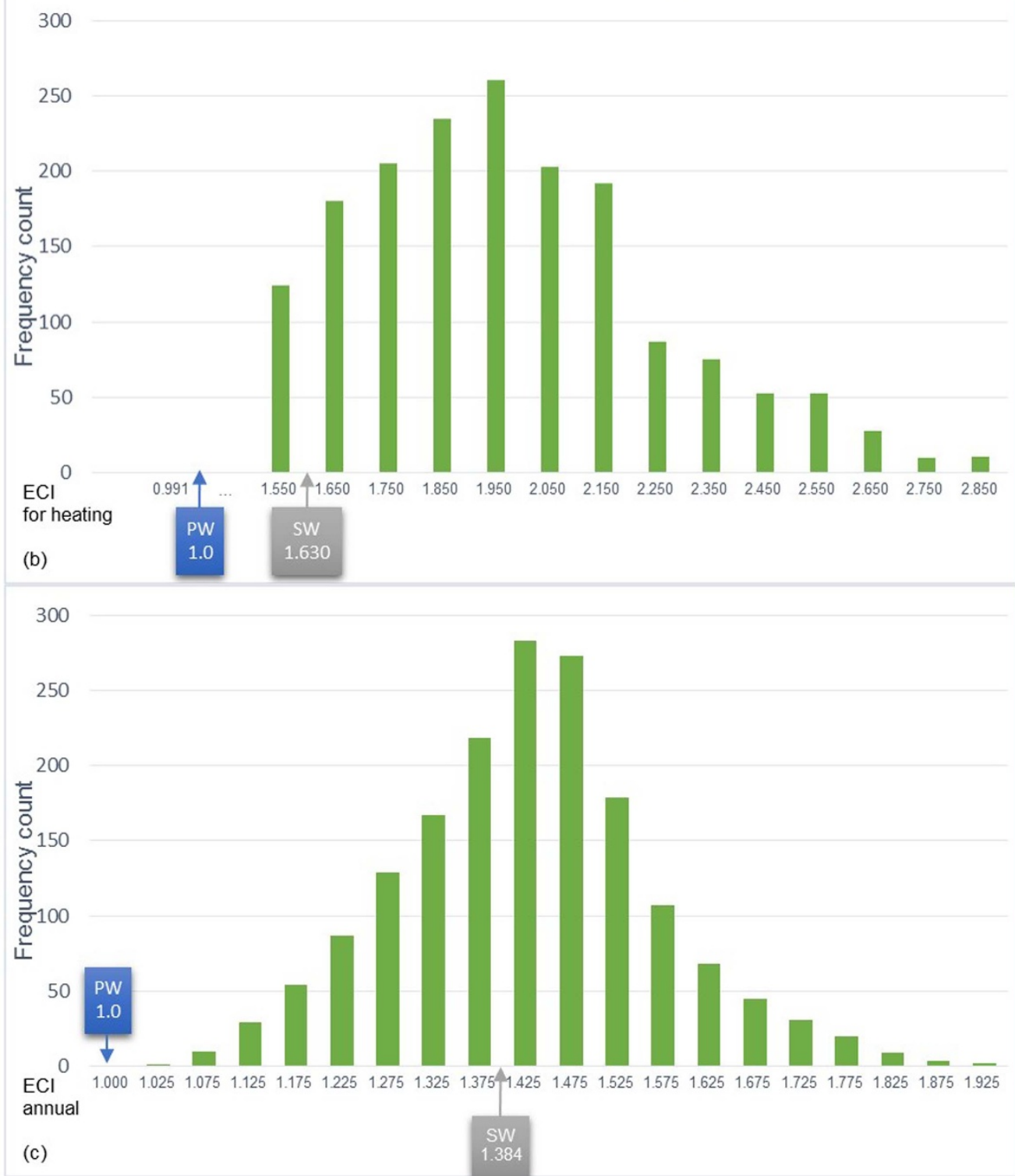

Figure 3 Energy Consumption Index (ECI) frequency counts for the cooling season, the heating season and an entire year at a transition temperature of $20^{\circ} \mathrm{C}$. Each thermochromic window has an ECI value. The ECI frequency counts represent the energy performance distribution for all of the thermochromic windows for (a) the cooling season, (b) the heating season and (c) an entire year. The ECI values of the perfect windows (PW) and the standard window (SW) are also shown. 


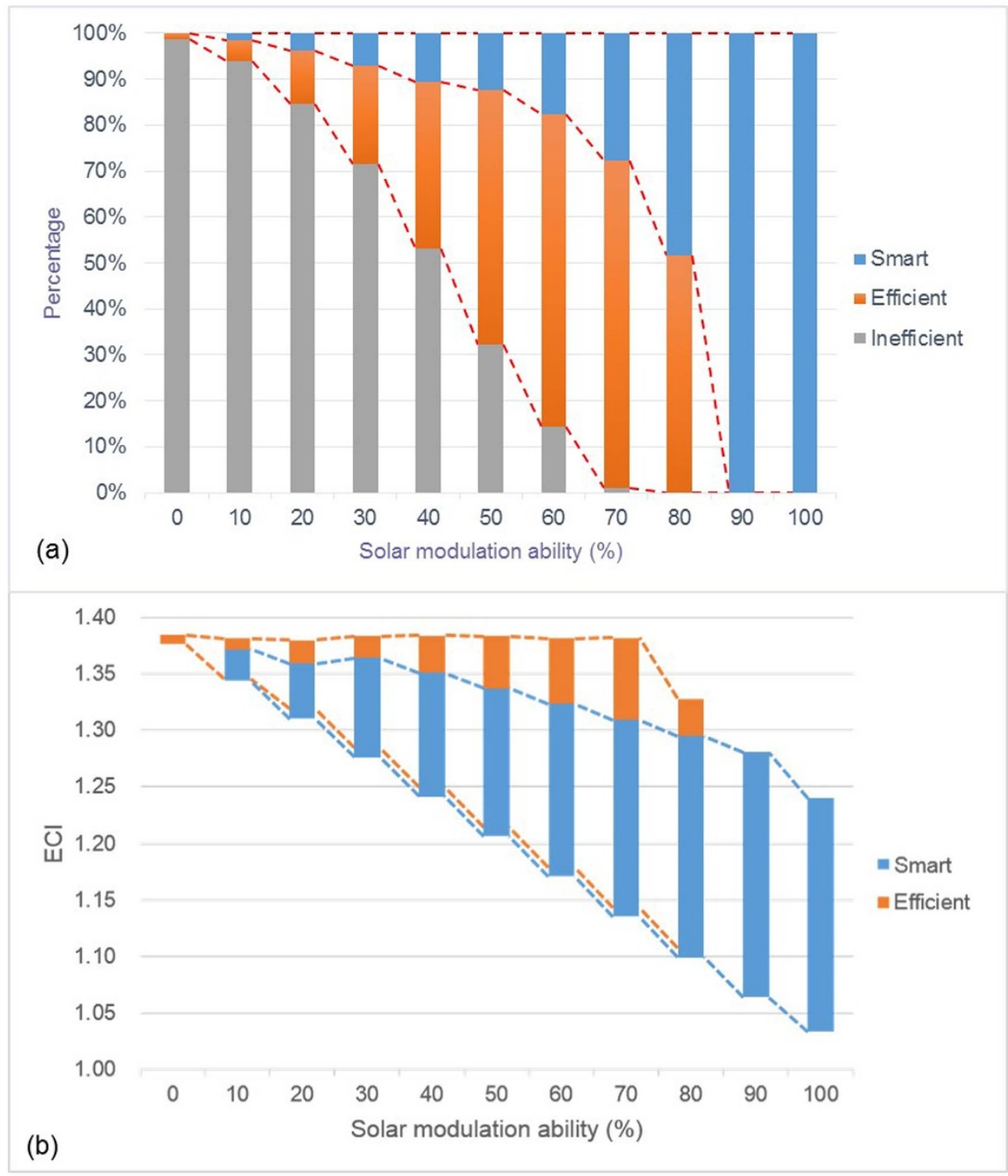

Figure $4 \mid$ Effect of the solar modulation ability on performance at a transition temperature of $20^{\circ} \mathrm{C}$. (a) The percentages of each behavior type at different solar modulation abilities. The percentages at each solar modulation ability are relative values. The absolute number of thermochromic windows decreases as the solar modulation ability increases. (b) The ECI ranges of smart and efficient windows at each solar modulation ability.

with identical coordinates (see Supplementary Figure S3 online). The largest coefficient of variation for the averaged ECIs is $5.64 \%$ (with a corresponding standard deviation and mean of 0.084 and 1.489 , respectively), which demonstrates the acceptability of using the averaged values.

As Figure 5 (a) shows, the ECI decreases as $\Delta \tau_{\text {solar }}$ increases and $\Delta \alpha_{\text {solar }}$ decreases. The lowest ECI for the entire year is obtained when $\Delta \tau_{\text {solar }}$ and $\Delta \alpha_{\text {solar }}$ are $100 \%$ and $0 \%$, respectively. For this ideal case, the solar absorptivity remains unchanged between the window's different states, meaning that the dramatic change in the solar transmittance is achieved by varying the solar reflectance. This mechanism of changing the solar transmittance is similar to that of the perfect window, so that the ECI for this case is close to unity and can be lowered further by the long-wave thermal radiation properties. There are two special lines in Figure 5 (a): the 1.384 contour (dashdot line) and the line on which $\Delta \tau_{\text {solar }}$ is equal to $\Delta \alpha_{\text {solar }}$ (dashed line). The former represents the annual ECI of the standard window. The ECIs to the left of the dash-dot line are greater than those of the standard window, making the thermochromic windows located in the left domain inefficient. The ECIs on the other side are lower, making the windows in the domain on the right efficient or smart.
It is observed that the inefficient windows have relatively small $\Delta \tau_{\text {solar }}$ values, and as $\Delta \alpha_{\text {solar }}$ increases, $\Delta \tau_{\text {solar }}$ must also be increased to make the window efficient or smart. Regarding the other (dashed) line, the thermochromic windows located in the domain above the line have a greater $\Delta \alpha_{\text {solar }}$ than $\Delta \tau_{\text {solar }}$. Because the solar transmittance in the transparent state $\left(\tau_{\text {solar, }}\right)$ is higher than that in the opaque state $\left(\tau_{\text {solar,o }}\right)$ and the solar absorptivity in the transparent state $\left(\alpha_{\text {solar, },}\right)$ is less than that in the opaque state $\left(\alpha_{\text {solar,o }}\right)$, the solar reflectance relationship between these two states, $\rho_{\text {solar, }}$ and $\rho_{\text {solar }, 0}$, is determined by the relationship between $\Delta \tau_{\text {solar }}\left(=\tau_{\text {solar,t }}-\tau_{\text {solar,o }}\right)$ and $\Delta \alpha_{\text {solar }}\left(=\alpha_{\text {solar,o }}-\alpha_{\text {solar, },}\right)$. The difference between $\rho_{\text {solar, } t}$ and $\rho_{\text {solar,o }}$ should be equal to the difference between $\Delta \alpha_{\text {solar }}$ and $\Delta \tau_{\text {solar }}$. If $\Delta \alpha_{\text {solar }}$ is greater than $\Delta \tau_{\text {solar }}$, then $\rho_{\text {solar, }}$ will be greater than $\rho_{\text {solar }, \mathrm{o} .}$ Otherwise, a higher $\Delta \tau_{\text {solar }}$ means a higher $\rho_{\text {solar,o }}$. A higher solar reflectance in the opaque state indicates that the reduced solar radiation transmitted into the building is partially reflected, rather than entirely absorbed, after the window transforms into its opaque state from the transparent state. The reflection of the solar radiation has a greater effect on the energy performance than the absorption due to the reduction in the transmitted solar radiation of the perfect window. Consequently, in the domain above the dashed line, the inef- 


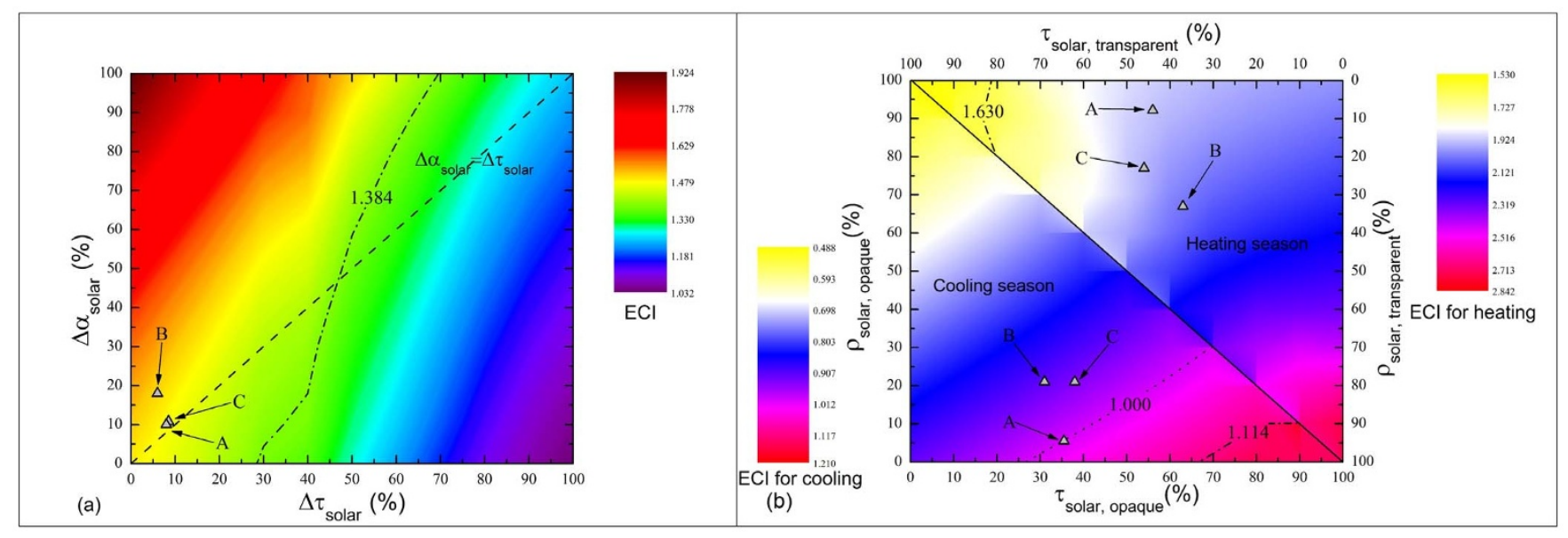

Figure 5 ECI contour for a particular thermochromic window. (a) The annual ECI contour. (b) ECI contours for the cooling season and the heating season. Using (a), inefficient windows can be identified, whereas smart or efficient windows can be identified using (b).

ficient area is much larger than elsewhere, and $\Delta \tau_{\text {solar }}$ must be larger to make the window efficient or smart. In the domain below the dashed line, the inefficient area is much smaller. This difference between the domains separated by the dashed line emphasizes the importance of reflection in improving thermochromic materials.

The energy performance of a particular thermochromic window can be found using Figure 5 (a). However, the smartness cannot be identified completely because only inefficient windows are distinct, whereas efficient and smart windows are mixed together. As Table 2 shows, efficient and smart windows cannot be distinguished using the annual ECI because both types have better energy performance than the standard window over the entire year. According to the definitions, they must be distinguished further by their performance during the cooling and heating seasons. Similarly to Figure 5 (a), the seasonal performance is shown in Figure 5 (b) using a color contour for the ECI. The abscissa and ordinate are the solar transmittance and solar reflectance, respectively. At a transition temperature of $20^{\circ} \mathrm{C}$, a window is primarily in its transparent state and its opaque state during the heating and cooling seasons, respectively, with the window radiation properties corresponding to the state in each season. The ECIs for the cooling and heating seasons are located in the lower left and upper right domains, respectively. In the cooling season, the ECI decreases as the solar transmittance decreases and the solar reflectance increases; in the heating season, the ECI decreases as the solar transmittance increases and the solar reflectance decreases. The ECIs during the cooling season are lower than those in the heating season, indicating that thermochromic windows provide better performance in the cooling season. The ECI contour lines for the standard window are shown with dash-dot lines, and the contour for the perfect window for summer is shown with a dotted line. The thermochromic windows located to the left of the dash-dot lines have lower ECIs than the standard window. It is apparent that the area in which the ECIs for the cooling season are less than 1.114 is much larger than the area in which the ECIs for the heating season are lower than 1.630, meaning that thermochromic windows are more likely to be advantageous during the cooling season. A particular thermochromic window's energy performance and smartness can be estimated using Figure 5: if the window is located in the advantageous regions for both seasons in Figure 5 (b), it is a smart window; if it is located in the advantageous region for only one season in Figure 5 (b), it will be an efficient window if it is to the right of the dash-dot line in Figure 5 (a) and an inefficient window otherwise; if the window is not located in the advantageous region for either season in Figure 5 (b), it is an inefficient window. The window's ECI over an entire year can be estimated from Figure 5 (a).
To bridge the gap between the existing materials and the discussed potential materials, three current $\mathrm{VO}_{2}$ samples were chosen to show how to characterize their energy performance and smartness. The summary of the spectral properties for $\mathrm{VO}_{2}-\mathrm{A}^{26}, \mathrm{~B}^{21}$ and $\mathrm{C}^{23}$ can be seen in the previous work ${ }^{18}$ (or see Supplementary Table 1 online). With the assumption of a transition temperature of $20^{\circ} \mathrm{C}$, they were located in Figure 5 according to their spectral properties. In Figure 5 (b), all these samples are located in the advantageous region for the cooling season, while in the disadvantageous region for the heating season, indicating the absence of a smart window for all these samples. Regarding the energy performance over the entire year, all of them are to the left of the dash-dot line in Figure 5 (a), meaning that they are inefficient windows without any energy-efficient benefit.

\section{Discussion}

Smart windows, such as thermochromic windows, are being developed rapidly because of their great energy saving potential in building applications. In addition to technical research on improving window properties, theoretical research should also be performed to guide the technical research. In this paper, the smartness of windows was discussed, providing general information on the smartness and energy performance of thermochromic windows.

The transition temperature of a thermochromic window should be low enough for the transition process to occur. In this study, we showed that a transition temperature of approximately $20^{\circ} \mathrm{C}$ would be optimal for smart windows. At this transition temperature, approximately $11 \%$ of the 1716 potential thermochromic windows were labeled as smart. The transition temperature can be controlled within a wide range, from $\sim 60^{\circ} \mathrm{C}$ to room temperature ${ }^{27}$. A transition temperature of $30^{\circ} \mathrm{C}$ is a common value at which enhanced optical properties are demonstrated ${ }^{28}$. Smart windows can be fabricated with this transition temperature; however, this will most likely be difficult because of the very small number of windows that are smart at this temperature. The use of materials with a transition temperature above $30^{\circ} \mathrm{C}$ may save energy consumption, but these materials behave only as common energy-efficient materials without intelligence. A solar control window may have the same energy performance as these thermochromic windows and would be preferred for its much lower cost.

Among the properties discussed in this study, the transition temperature is a significant factor that affects a thermochromic window's energy performance, but it is not the sole factor because even at a transition temperature of $20^{\circ} \mathrm{C}$, most windows are inefficient. For a particular transition temperature, the solar modulation ability and solar absorption variation dominate the energy performance. 
However, the solar modulation ability of most current thermochromic windows is below $10 \%{ }^{28,29}$. This is quite a poor value because windows with this value are predominantly inefficient according to Figure 5 (a). For a window to behave as an efficient or smart window, its solar modulation ability must be increased to $\sim 30 \%$, and its solar absorption variation should be near zero. A low solar absorption variation means that the solar transmittance is regulated partly via reflection. Although undesirable solar radiation is regulated via absorption in all of the thermochromic windows in this study, the windows whose solar absorption variation is less than their solar modulation ability are more likely to be efficient or smart, which demonstrates the importance of reflection. The best energy performance can be achieved at zero solar absorption variation, with an ECI very close to that of the perfect window. Although the regulation of long-wave thermal radiation properties is beyond this study's scope, their effect on energy performance should not be ignored. As our previous study concluded ${ }^{30}$, perfect windows could be achieved through the simultaneous control of solar spectrum properties and long-wave thermal properties.

Through the discussion, we can reach the following conclusions. The energy-efficient performance is improved with the increase in the solar modulation ability (the difference in solar transmittance between the transparent state and the opaque state) and the decrease in the solar absorption variation (the difference in the solar absorptivity between the transparent state and the opaque state). Regarding the specific demands of being smart thermochromic glazing, first the transition temperature should be near $20^{\circ} \mathrm{C}$ because at this transition temperature the glazing will most likely be smart. Then its solar modulation ability must be increased to $\sim 30 \%$. In addition, the solar absorption variation should be near zero. For a particular thermochromic material, its specific energy-efficient performance can be estimated through the color contours.

\section{Methods}

Building Energy program. This modeling software was compiled based on a nonsteady-state heat transfer model. In the software, the building envelope and the indoor and outdoor air were divided into hundreds of nodes. For each node, the energy conservation equation was based on the implicit difference method. The equations for all of the nodes in the temperature field formed a matrix. The temperature field was determined by solving the matrix via the Gauss-Seidel iteration method. The transition hysteresis width and gradient of the thermochromic materials can also influence the energy-efficient performance. However, these transition properties were not discussed further in this study. Comprehensive researches on these properties have been performed by the Binions group ${ }^{16,17}$. BuildingEnergy has been validated using ANSI/ASHRAE Standard 140-2004 ("Standard Method of Test for the Evaluation of Building Energy Analysis Computer Programs") in our previous work $^{2}$. We also validated the program through a series of experiments conducted in full-size rooms ${ }^{31}$

Details of the residential room. The room is assumed to be in a middle story of a multi-story residential building. The room has internal dimensions of $4 \times 3.3 \times$ $2.8 \mathrm{~m}^{3}$ (length $\times$ width $\times$ height) and contains only one exterior wall, with a $1.5 \times$ $1.5 \mathrm{~m}^{2}$ single-glazed window in the center of the wall. The inner heat gain from the occupants and equipment is taken to be $4.3 \mathrm{~W}$ per unit of floor area, and the heat gain from the lighting is $3.5 \mathrm{~W}$ per unit of floor area while the lights are on, from 18:00 until 22:00 each day. The ventilation rate is set as 1.0 air changes per hour (ACH) when the space cooling or heating is operating and $10.0 \mathrm{ACH}$ at all other times. There are two primary simulation hypotheses in BuildingEnergy: (1) the indoor temperature of the room and the adjacent rooms are assumed to be the same, and therefore, there is no heat transfer via the interior walls; and (2) the heat transfer via the exterior wall and glazing is assumed to be one-dimensional. The climate data used in BuildingEnergy were the typical yearly meteorological data provided by the Chinese Architecture-specific Meteorological Data Sets for Thermal Environment Analysis.

1. Baetens, R., Jelle, B. P. \& Gustavsen, A. Properties, requirements and possibilities of smart windows for dynamic daylight and solar energy control in buildings: A state-of-the-art review. Sol. Energ. Mat. Sol. C. 94, 87-105 (2010).

2. Jelle, B. P. et al. Fenestration of today and tomorrow: A state-of-the-art review and future research opportunities. Sol. Energ. Mat. Sol. C. 96, 1-28 (2012).

3. Sabry, M., Eames, P., Singh, H. \& Wu, Y. Smart windows: Thermal modelling and evaluation. Sol. Energy 103, 200-209 (2014).
4. Warwick, M. E. et al. Synthesis and energy modelling studies of titanium oxynitride films as energy efficient glazing. Sol. Energ. Mat. Sol. C. 118, 149-156 (2013).

5. Ye, H., Meng, X. \& Xu, B. Theoretical discussions of perfect window, ideal near infrared solar spectrum regulating window and current thermochromic window. Energ. Buildings 49, 164-172 (2012).

6. Granqvist, C. G. Transparent conductors as solar energy materials: A panoramic review. Sol. Energ. Mat. Sol. C. 91, 1529-1598 (2007).

7. Granqvist, C. G., Lansåker, P., Mlyuka, N., Niklasson, G. \& Avendano, E. Progress in chromogenics: new results for electrochromic and thermochromic materials and devices. Sol. Energ. Mat. Sol. C. 93, 2032-2039 (2009).

8. Rosencrantz, T., Bülow-Hübe, H., Karlsson, B. \& Roos, A. Increased solar energy and daylight utilisation using anti-reflective coatings in energy-efficient windows. Sol. Energ. Mat. Sol. C. 89, 249-260 (2005).

9. Kamalisarvestani, M., Saidur, R., Mekhilef, S. \& Javadi, F. Performance, materials and coating technologies of thermochromic thin films on smart windows. Renew. Sust. Energ. Rev. 26, 353-364 (2013).

10. Hoffmann, S., Lee, E. S. \& Clavero, C. Examination of the technical potential of near-infrared switching thermochromic windows for commercial building applications. Sol. Energ. Mat. Sol. C. 123, 65-80 (2014).

11. Lee, E. S., Pang, X., Hoffmann, S., Goudey, H. \& Thanachareonkit, A. An empirical study of a full-scale polymer thermochromic window and its implications on material science development objectives. Sol. Energ. Mat. Sol. C. 116, 14-26 (2013).

12. Tan, X. et al. Unraveling Metal-insulator Transition Mechanism of $\mathrm{VO}_{2}$ Triggered by Tungsten Doping. Sci. Rep. 2, 466-471 (2012).

13. Li, S.-Y., Niklasson, G. A. \& Granqvist, C. G. Thermochromic fenestration with $\mathrm{VO}_{2}$-based materials: Three challenges and how they can be met. Thin Solid Films 520, 3823-3828 (2012).

14. Li, S.-Y., Niklasson, G. A. \& Granqvist, C.-G. Nanothermochromics: Calculations for $\mathrm{VO}_{2}$ nanoparticles in dielectric hosts show much improved luminous transmittance and solar energy transmittance modulation. J Appl Phys 108, 063525 (2010).

15. Warwick, M. E. \& Binions, R. Advances in thermochromic vanadium dioxide films. J. Mater. Chem. A 2, 3275-3292 (2014).

16. Warwick, M. E., Ridley, I. \& Binions, R. The effect of transition hysteresis width in thermochromic glazing systems. Open Journal of Energy Efficiency 2, 75 (2013).

17. Warwick, M. E., Ridley, I. \& Binions, R. The effect of transition gradient in thermochromic glazing systems. Energ. Buildings 77, 80-90 (2014).

18. Ye, H. \& Long, L. Smart or not? A theoretical discussion on the smart regulation capacity of vanadium dioxide glazing. Sol. Energ. Mat. Sol. C. 120, 669-674 (2014).

19. Voti, R. L., Larciprete, M. C., Leahu, G., Sibilia, C. \& Bertolotti, M. Optimization of thermochromic $\mathrm{VO}_{2}$ based structures with tunable thermal emissivity. J Appl Phys 112, 034305 (2012).

20. Zhang, Z. et al. Solution-based fabrication of vanadium dioxide on F: SnO2 substrates with largely enhanced thermochromism and low-emissivity for energysaving applications. Energ. Environ. Sci. 4, 4290-4297 (2011).

21. Mlyuka, N. R., Niklasson, G. A. \& Granqvist, C. G. Thermochromic $\mathrm{VO}_{2}$-based multilayer films with enhanced luminous transmittance and solar modulation. Phys. Status Solidi A 206, 2155-2160 (2009).

22. Zhang, Z. et al. Thermochromic $\mathrm{VO}_{2}$ Thin Films: Solution-Based Processing, Improved Optical Properties, and Lowered Phase Transformation Temperature. Langmuir: the ACS journal of surfaces and colloids 26, 10738-10744 (2010).

23. Saeli, M., Piccirillo, C., Parkin, I. P., Binions, R. \& Ridley, I. Energy modelling studies of thermochromic glazing. Energ. Buildings 42, 1666-1673 (2010).

24. American-Society-for-Testing-and-Materials(ASTM-G173-03). Reference Solar Spectral Irradiance: Air Mass 1.5, < http://rredc.nrel.gov/solar/spectra/am1.5/> (date of accse: 11/01/2012).

25. MOHURD. Design standard for energy efficiency of residential buildings in hot summer and cold winter zone (JGJ 134-2010). 1st edn (China Architecture \& Building Press, 2010).

26. Gao, Y. et al. Enhanced chemical stability of $\mathrm{VO}_{2}$ nanoparticles by the formation of $\mathrm{SiO}_{2} / \mathrm{VO}_{2}$ core/shell structures and the application to transparent and flexible $\mathrm{VO}_{2}$-based composite foils with excellent thermochromic properties for solar heat control. Energ. Environ. Sci. 5, 6104-6110 (2012).

27. Blackman, C. S., Piccirillo, C., Binions, R. \& Parkin, I. P. Atmospheric pressure chemical vapour deposition of thermochromic tungsten doped vanadium dioxide thin films for use in architectural glazing. Thin Solid Films 517, 4565-4570 (2009).

28. Zhou, M. et al. Periodic porous thermochromic $\mathrm{VO}_{2}$ (M) films with enhanced visible transmittance. Chem. Commun. 49, 6021-6023 (2013).

29. Zhou, J. et al. $\mathrm{VO}_{2}$ thermochromic smart window for energy savings and generation. Sci. Rep. 3, 3029-3033 (2013).

30. Ye, H., Meng, X., Long, L. \& Xu, B. The route to a perfect window. Renew. Energ. 55, 448-455 (2013).

31. Ye, H. et al. The demonstration and simulation of the application performance of the vanadium dioxide single glazing. Sol. Energ. Mat. Sol. C. 117, 168-173 (2013).

\section{Acknowledgements}

This work was funded by the National Basic Research Program of China (Grant No. 2009CB939904). 


\section{Author contributions}

H.Y. conceived the idea, co-wrote the paper and supervised the whole project. L.L. realized the idea, carried out the simulation calculations, analyzed data, created figures and wrote the paper. Both of the authors discussed the results, commented on and revised the manuscript.

\section{Additional information}

Supplementary information accompanies this paper at http://www.nature.com/ scientificreports

Competing financial interests: The authors declare no competing financial interests.
How to cite this article: Long, L. \& Ye, H. How to be smart and energy efficient: A general discussion on thermochromic windows. Sci. Rep. 4, 6427; DOI:10.1038/srep06427 (2014).

(c) (1) $\odot$ This work is licensed under a Creative Commons Attribution-NonCommercialNoDerivs 4.0 International License. The images or other third party material in this article are included in the article's Creative Commons license, unless indicated otherwise in the credit line; if the material is not included under the Creative Commons license, users will need to obtain permission from the license holder in order to reproduce the material. To view a copy of this license, visit http:// creativecommons.org/licenses/by-nc-nd/4.0/ 